\title{
Temperature-Sensitive Sol-Gel Transition Behavior of Biodegradable Four-Arm Star-Shaped PEG-PLGA Block Copolymer Aqueous Solution
}

\author{
By Su Jeong LEE, Chung Won PARK, and Sung Chul KIM*
}

Biodegradable four-arm star-shaped poly(ethylene glycol- $b$-DL-lactic acid-co-glycolic acid) block copolymers (4arm PEGPLGA) were synthesized by ring-opening polymerization of DL-lactide and glycolide using 4arm PEG as an initiator and $\mathrm{Sn}(\mathrm{oct})_{2}$ as a catalyst. In aqueous solution, they showed reversible sol to gel to sol transition behavior while increasing the temperature from $0{ }^{\circ} \mathrm{C}$ to $40^{\circ} \mathrm{C}$. The larger the molecular weight or the stronger the relative hydrophobicity of the hydrophobic PLGA block, the smaller the critical gel concentration (CGC). 4arm PEG-PLGA formed gels at lower CGC (13 wt \%) than the inverse 4arm PLGA-PEG $(24 \mathrm{wt} \%)$ due to the differences in their molecular structures.

KEY WORDS: Hydrogels / Star Polymers / Sol-gel Transition / Biodegradable /

Temperature-sensitive polymers of which aqueous solutions undergo sol-gel transition in response to temperature changes are especially attractive in drug delivery applications as an in situ gel-forming device. These polymers might be mixed with therapeutic agents such as drugs, cells or proteins in the sol state and injected using a syringe into the body to form a depot system. ${ }^{1-7}$ Many kinds of temperature-sensitive biodegradable block copolymers consisting of poly(ethylene glycol) (PEG) and biodegradable polyester such as poly(L-lactic acid) (PLLA), poly(DL-lactic acid) (PDLLA), poly(DL-lactic acidco-glycolic acid) (PLGA), and poly( $\varepsilon$-caprolactone) (PCL) were studied for this purpose. ${ }^{5,8-16} \mathrm{Kim}$ et al. studied the gelation behavior of PEG-PLGA-PEG with PEG having fixed molecular weight of 550 and PLGA having various molecular weights and various ratios of DL-lactide to glycolide, which showed gel to sol transition (upper boundary curve) and sol to gel transition (lower boundary curve) as the temperature was increased. ${ }^{5}$ Lee et al. reported that PLGA-PEG-PLGA triblock copolymer with a central PEG block demonstrated an interesting reversible sol-gel transition in water. The CGC of this polymer was lower than that of typical PEG-PLGA-PEG, which was due to the bridge connections between micelles in PLGA-PEG-PLGA system. ${ }^{13,14}$

In our previous work, we reported the sol-gel transition and micellization behaviors of biodegradable, non-toxic and temperature-sensitive three-arm star-shaped PLLA-PEO $\left(M_{\mathrm{n}, \mathrm{PEO}}=2000\right.$ and 5000), which showed only gel to sol transition (upper boundary curve) at high concentration (above $10 \mathrm{wt} \%){ }^{15,16}$ This work is thought to be the first reported study on the gelation behavior of block copolymers with star-shaped architecture. We also developed biodegradable three-arm and four-arm star-shaped PLGA-PEG block copolymers (3arm PLGA-PEG and 4arm PLGA-PEG) with PEG having fixed molecular weight of 550 and observed their sol-gel-sol transition in high concentration regions (above $24 \mathrm{wt} \%$ ). ${ }^{17}$
Recently, we synthesized and characterized biodegradable four-arm star-shaped PEG-PLGA block copolymers (4arm PEG-PLGA) with the reverse molecular structure to $4 \mathrm{arm}$ PLGA-PEG to study the effect of the structure on gelation behavior in star-shaped block copolymers. The molecular weight of 4arm PEG was fixed and the molecular weight and the mole ratio of DL-lactide to glycolide of PLGA block were varied by the feed mole ratios of DL-lactide, glycolide, and 4arm PEG. The effects of the PLGA molecular weight, PLGA composition and topological variation (4arm PLGA-PEG vs 4arm PEG-PLGA) on the sol-gel transition were investigated by the tube-tilting method.

\section{EXPERIMENTAL SECTION}

\section{Materials}

4arm PEG $\left(\mathrm{C}_{\left(\mathrm{CH}_{2}\right.}\left[\mathrm{CH}_{2} \mathrm{CH}_{2} \mathrm{O}\right]_{10} \mathrm{H}\right)_{4}, M_{\mathrm{w}}$ (from hydroxyl value $=2022$ ) was purchased from NOF Co. and used after drying in vacuo at $80^{\circ} \mathrm{C}$ for $10 \mathrm{~h}$. 1,4-dioxan-2,5-dione (glycolide, Boehringer Ingelheim), 3,6-Dimethyl-1,4-dioxane2,5-dione (DL-lactide, Aldrich, USA), stannous 2-ethylhexanoate (Stannous octoate, $\mathrm{Sn}(\mathrm{oct})_{2}$, Sigma, USA) were used as received without further purification. As the reaction solvent, chloroform (Junsei) and diethyl ether were used without purification. Deuterated chloroform $\left(\mathrm{CDCl}_{3} ; 99.9\right.$ atom \% D) for NMR measurements was purchased from Aldrich and tetrahydrofuran for GPC measurement was purchased from Baker. All other reagents were of reagent grade and used as received.

\section{Synthesis of Star-shaped 4Arm PEG-PLGA Block Copoly- mer \\ Star-shaped 4arm PEG-PLGA block copolymer was synthe- sized by bulk ring-opening polymerization of DL-lactide and glycolide using 4arm PEG as a multifunctional initiator in the}




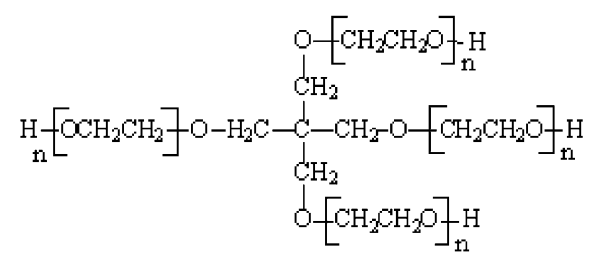

4arm PEG

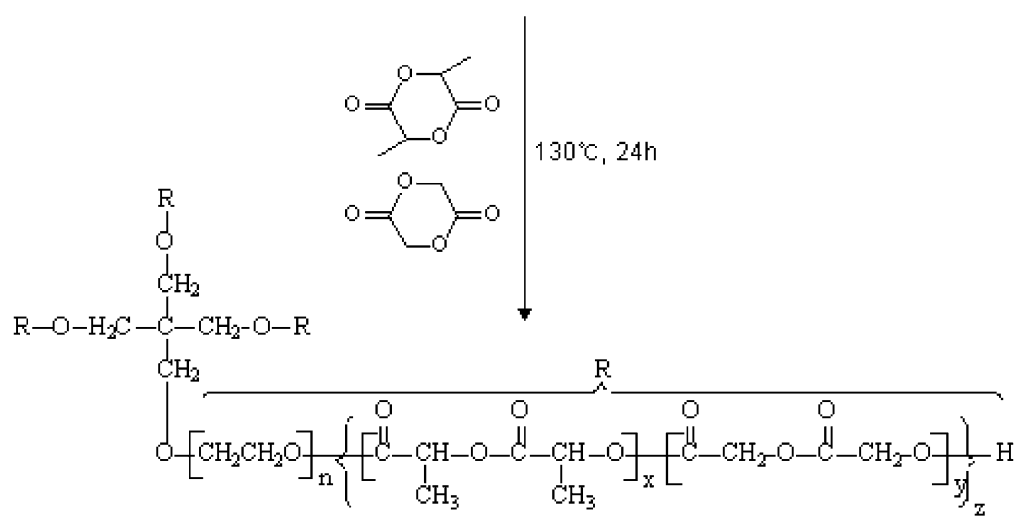

4 arm PEGPLGA

Scheme 1. Synthesis of 4arm PEG-PLGA.

presence of stannous octoate $\left(\mathrm{Sn}(\mathrm{oct})_{2}\right)$ as a catalyst. The molecular weight of 4 arm PEG was fixed, while the molecular weight of PLGA block and the ratio of DL-lactide to glycolide in PLGA block were varied, which were controlled by varying the feed mole ratios of DL-lactide, glycolide, and 4arm PEG.

As shown in Scheme 1, the synthesis procedure of $4 \mathrm{arm}$ PEG-PLGA8 with [LA]:[GA] mole ratio of 75:25 was as follows: DL-lactide $(0.021 \mathrm{~mol})$, glycolide $(0.007 \mathrm{~mol})$, dried 4arm PEG $(0.00087 \mathrm{~mol})$ and $\mathrm{Sn}(\mathrm{oct})_{2} \quad(0.5 \mathrm{~mol} \%$ of the monomer, $0.00014 \mathrm{~mol}$ ) were added into a round-bottom flask in a glove box and then reacted in bulk at $130{ }^{\circ} \mathrm{C}$ for $24 \mathrm{~h}$ under nitrogen. After the polymerization was completed, the product was cooled to room temperature, dissolved in chloroform and precipitated in diethyl ether. The precipitated product was dried in vacuo at room temperature overnight to obtain 4arm PEGPLGA.

\section{Characterizations}

${ }^{1} \mathrm{H}$ and ${ }^{13} \mathrm{C}$ NMR spectra were recorded using a Bruker AMX 500 spectrometer in $\mathrm{CDCl}_{3}-\mathrm{d}$ (Aldrich) to confirm the structure of synthesized 4arm PEG-PLGA. The molecular weight of the synthesized polymer can be calculated from the area of proton peak in ${ }^{1} \mathrm{H}$ NMR spectra.

GPC was performed using a Polymer Laboratories GPC 220 equipped with a differential refractometer detector and a light scattering detector of 15 and 90 angle at $35^{\circ} \mathrm{C}$ to determine the molecular weight and molecular weight distribution. GPC was calibrated with five mono-disperse polystyrene standards. THF (Baker) was used as an eluent with $1 \mathrm{~mL} / \mathrm{min}$ flow rate.

Sample was named by the following way: For example, "4arm PEG-P $\left(\mathrm{L}_{75} \mathrm{G}_{25}\right) 8$ " indicates that this polymer is star- shaped block copolymer composed of 4arm PEG with fixed molecular weight and PLGA block with 8 monomeric units in one arm and [LA]:[GA] mole ratio of 75:25.

\section{Phase Diagram}

The sol (flow)-gel (no flow) transition behavior of 4arm PEG-PLGA in aqueous solution was investigated by the tube tilting method. This simple method of detecting gelation has been shown to agree well with the sol-gel phase boundary determined by rheometry and differential scanning calorimetry. ${ }^{18}$ Each sample with a given concentration was prepared by dissolving the polymer in ultrapure water in a $5 \mathrm{~mL}$ vial at $4{ }^{\circ} \mathrm{C}$ for 2-3 d. The vial was immersed in a water bath at each temperature for $20 \mathrm{~min}$ to equilibrate the solution. Experimental temperature-increment was $2{ }^{\circ} \mathrm{C}$. The sol-gel transition temperature was determined by tilting the vials with $90^{\circ}$ for $1 \mathrm{~min}$. If there is no flow in $1 \mathrm{~min}$, it was regarded as a gel state.

The sol-gel transition of the polymer aqueous solution was also investigated by viscometer (Brookfield Viscometer DV-III ultra with programmable rheometer). The viscosity measurement in the vessel was performed using a tight cap to prevent the evaporation of water in polymer solution. The viscosity of the polymer solution was investigated using a T-F spindle at $0.2 \mathrm{rpm}$ from 5 to $40^{\circ} \mathrm{C}$ in increments of $1^{\circ} \mathrm{C}$. The temperature was controlled by the circulating baths with a programmable controller (TC-502P).

\section{CMC and Micelle Size}

Critical micelle concentration (CMC) was determined by dye solubilization method using 1,6-diphenyl-1,3,5-hexatriene (DPH, Aldrich) as a dye at $20^{\circ} \mathrm{C}$. $0.5 \mathrm{mM} \mathrm{DPH}$ solution 

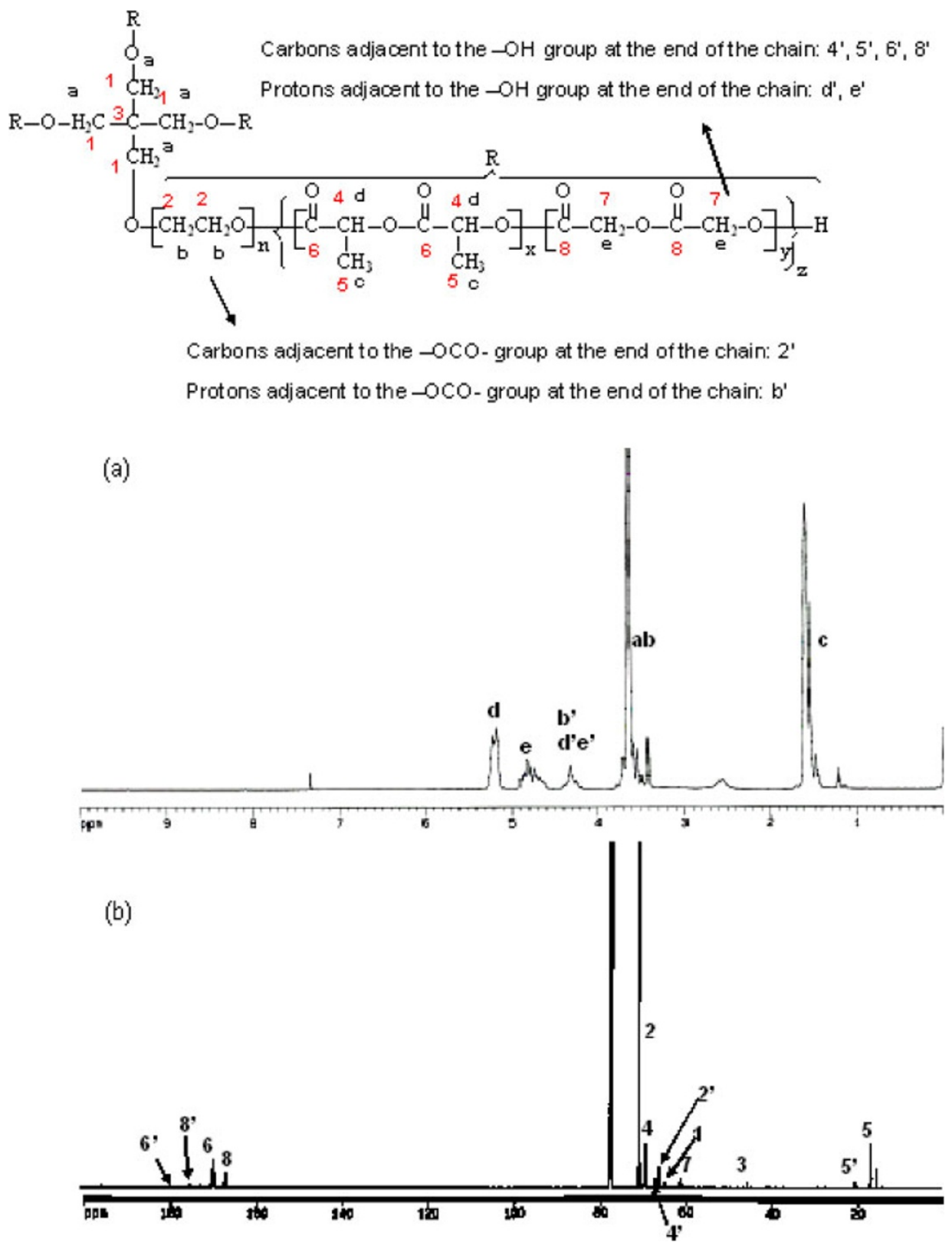

Figure 1. (a) ${ }^{1} \mathrm{H}$ NMR and (b) ${ }^{13} \mathrm{C}$ NMR spectra of 4arm $\mathrm{PEG}-\mathrm{P}\left(\mathrm{L}_{75} \mathrm{G}_{25}\right) 8$.

$(24 \mu \mathrm{L})$ in methanol was added into the aqueous polymer solution $(2.4 \mathrm{~mL})$ at given concentration. UV-visible spectra were recorded by Jasco V-530 spectrophotometer with ETC$505 \mathrm{~T}$ thermostat system. The scan range was from $300 \mathrm{~nm}$ to $400 \mathrm{~nm}$. CMC was determined as the cross point of the two extrapolated straight lines when the absorbance at $378 \mathrm{~nm}$ relative to that at $400 \mathrm{~nm}$ was plotted.

The effective micelle diameter of the star-block copolymer in an aqueous solution was measured by DLS (Brookhaven Instruments BI-200SM) with $532 \mathrm{~nm}$ laser source with increasing temperature from 5 to $40{ }^{\circ} \mathrm{C}$. The temperature was controlled within $\pm 0.1^{\circ} \mathrm{C}$ with a Fisher water bath. The temperature increment was $5^{\circ} \mathrm{C}$ and the samples were immersed for $20 \mathrm{~min}$ at each increment to reach thermal equilibrium.

\section{RESULTS AND DISCUSSIONS}

Characterizations of 4Arm PEG-PLGA Block Copolymer

4arm PEG-PLGA was successfully synthesized by polymerizing DL-lactide and glycolide onto 4arm PEG as a multifunctional initiator and $\mathrm{Sn}(\mathrm{oct})_{2}$ as a catalyst in bulk at $130^{\circ} \mathrm{C}$.

In Figure 1, ${ }^{1} \mathrm{H}$ NMR spectra of 4arm PEG-P $\left(\mathrm{L}_{75} \mathrm{G}_{25}\right) 8$ clearly shows that besides the characteristic peaks of the main chains in the DL-lactide and glycolide at $5.20 \mathrm{ppm}$ (LA-C$)$, $1.55 \mathrm{ppm}\left(\mathrm{LA}-\mathrm{CH}_{3}\right)$, and $4.80 \mathrm{ppm}\left(\mathrm{GA}-\mathrm{CH}_{2}\right)$ and the characteristic peak of $4 \mathrm{arm} \mathrm{PEG}$ at $3.65 \mathrm{ppm}$, there are additional peaks of $\mathrm{LA}-\mathrm{CH}$ and $\mathrm{GA}-\mathrm{CH}_{2}$ adjacent to the end hydroxyl 
group $\left(\mathrm{d}^{\prime}, \mathrm{e}^{\prime}\right)$ and $4 \mathrm{arm} \mathrm{PEG}-\mathrm{CH}_{2}$ adjacent to the ester group $\left(\mathrm{b}^{\prime}\right)$ at $4.31 \mathrm{ppm}$.

The molecular weight of 4arm PEG-PLGA from NMR was calculated from the area of the characteristic peaks of $4 \mathrm{arm}$ PEG, DL-lactide, and glycolide on the basis of the total area of $\mathrm{d}^{\prime}, \mathrm{e}^{\prime}$, and $\mathrm{b}^{\prime}$ at $4.31 \mathrm{ppm}$ in ${ }^{1} \mathrm{H}$ NMR. It was assumed that DLlactide and glycolide were placed at the chain ends of the resulting block copolymers with same probability. If the ratio of DL-lactide to glycolide was $\mathrm{R}$, the molecular weight was calculated by the following equation.

$$
\begin{gathered}
\mathrm{d}^{\prime}=\mathrm{R} /(1+\mathrm{R}), \quad \mathrm{e}^{\prime}=2 /(1+\mathrm{R}) \\
\mathrm{A}_{\mathrm{b}^{\prime} \mathrm{d}^{\prime} \mathrm{e}^{\prime}}: \mathrm{A}_{\mathrm{ab}}=\mathrm{d}^{\prime}+\mathrm{e}^{\prime}+2: 4 \mathrm{n}, \\
M_{\mathrm{n}, 4 \text { arm PEG }}=176 \mathrm{n}+136 \\
\mathrm{~A}_{\mathrm{b}^{\prime} \mathrm{d}^{\prime} \mathrm{e}^{\prime}}: \mathrm{A}_{\mathrm{d}}=\mathrm{d}^{\prime}+\mathrm{e}^{\prime}+2: 2 \mathrm{x}-\mathrm{d}^{\prime}, \\
M_{\mathrm{n}, \text { PLA }}=144 \mathrm{x}, \\
\mathrm{A}_{\mathrm{b}^{\prime} \mathrm{d}^{\prime} \mathrm{e}^{\prime}}: \mathrm{A}_{\mathrm{e}}=\mathrm{d}^{\prime}+\mathrm{e}^{\prime}+2: 4 \mathrm{y}-\mathrm{e}^{\prime} \\
M_{\mathrm{n}, \text { PGA }}=116 \mathrm{y} \\
M_{\mathrm{n}, 4 \text { arm PEG-PLGA }}=M_{\mathrm{n}, 4 \text { arm PEG }}+4\left(M_{\mathrm{n}, \text { PLA }+} M_{\mathrm{n}, \text { PGA }}\right)
\end{gathered}
$$

In ${ }^{13} \mathrm{C}$ NMR spectra of 4 arm PEG-P $\left(\mathrm{L}_{75} \mathrm{G}_{25}\right) 8$ (Figure 1), the original peak of 4arm PEG- $\underline{\mathrm{CH}}_{2}$ adjacent to the hydroxyl group at $61.69 \mathrm{ppm}$ disappeared and a new peak $\left(2^{\prime}\right)$ at $65.85 \mathrm{ppm}$ appeared. It was confirmed that all the hydroxyl groups of 4arm PEG initiated polymerization to 4arm PEG-PLGA. The peaks of LA- $\underline{C H}, \mathrm{LA}-\underline{\mathrm{CH}}_{3}$, and LA- $\underline{\mathrm{C}}=\mathrm{O}$ adjacent to the end hydroxyl group $\left(4^{\prime}, 5^{\prime}, 6^{\prime}\right)$ in DL-lactide were shifted to $66.71,20.50$, and $175 \mathrm{ppm}$, respectively. For glycolide, GA-C$=\mathrm{O}$ adjacent to the end hydroxyl group $\left(8^{\prime}\right)$ was shifted to $173 \mathrm{ppm}$.

GPC curve of the typical 4arm PEG-PLGA block copolymer was shifted toward a higher molecular weight region than that of its original 4arm PEG and the polydispersity index (PDI $=1.17-1.18)$ of 4arm PEG-PLGA was rather small in every case. Such a narrow and unimodal GPC trace also confirmed the successful polymerization of star-shaped 4arm PEG-PLGA block copolymer (Figure 2).

Table I summarizes the molecular weights of 4arm PEGPLGAs measured by GPC, calculated from ${ }^{1} \mathrm{H}$ NMR and calculated from feed ratios. $M_{\mathrm{n}, \mathrm{NMR}}$ is in good agreement with

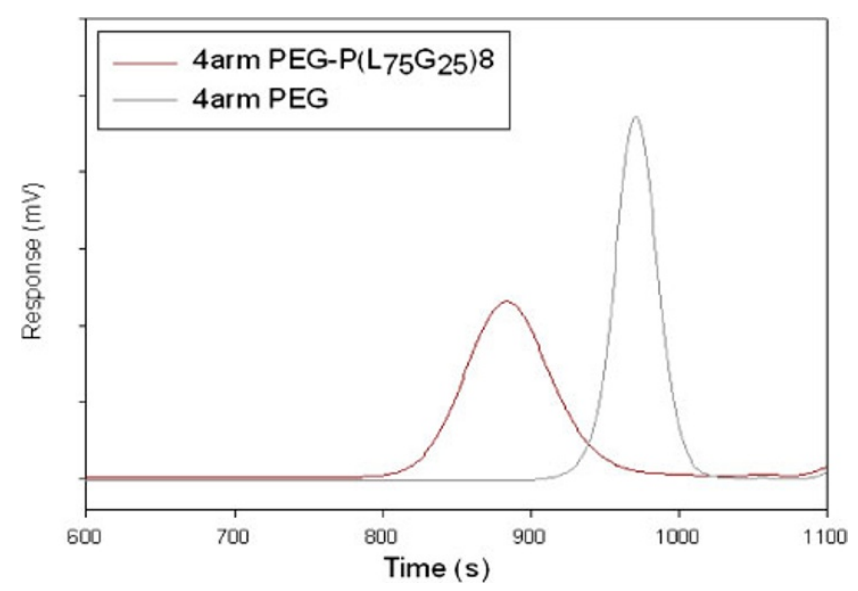

Figure 2. GPC trace of 4 arm $P E G$ and 4 arm $P E G-P\left(L_{75} G_{25}\right) 8$.
Table I. Molecular weights and molecular weight distributions of 4arm PEG-PLGAs

\begin{tabular}{ccccccc}
\hline Sample & $M_{\mathrm{n}, \mathrm{th}}{ }^{\mathrm{a}}$ & $M_{\mathrm{n}, \mathrm{NMR}}$ & $M_{\mathrm{n}, \mathrm{GPC}}$ & $M_{\mathrm{w}, \mathrm{GPC}}$ & $\mathrm{PDI}^{\mathrm{b}}$ & $\begin{array}{c}\text { PEG content } \\
\text { (wt \%) }\end{array}$ \\
\hline 4arm PEG-P $\left(\mathrm{L}_{75} \mathrm{G}_{25}\right) 7$ & 5735 & 5740 & 7470 & 8710 & 1.17 & 34 \\
4arm PEG-P $\left(\mathrm{L}_{75} \mathrm{G}_{25}\right) 8$ & 6284 & 6120 & 7970 & 9400 & 1.18 & 30 \\
4arm PEG-P $\left(\mathrm{L}_{50} \mathrm{G}_{50}\right) 8$ & 6059 & 6050 & 7800 & 9090 & 1.17 & 31 \\
\hline
\end{tabular}

a Theoretical $M_{\mathrm{n}}$ obtained from the feed ratios. ${ }^{\mathrm{b}}$ Polydispersity index $\left(M_{\mathrm{w}} / M_{\mathrm{n}}\right) .{ }^{\mathrm{c}}$ Determined by ${ }^{1} \mathrm{H}$ NMR.

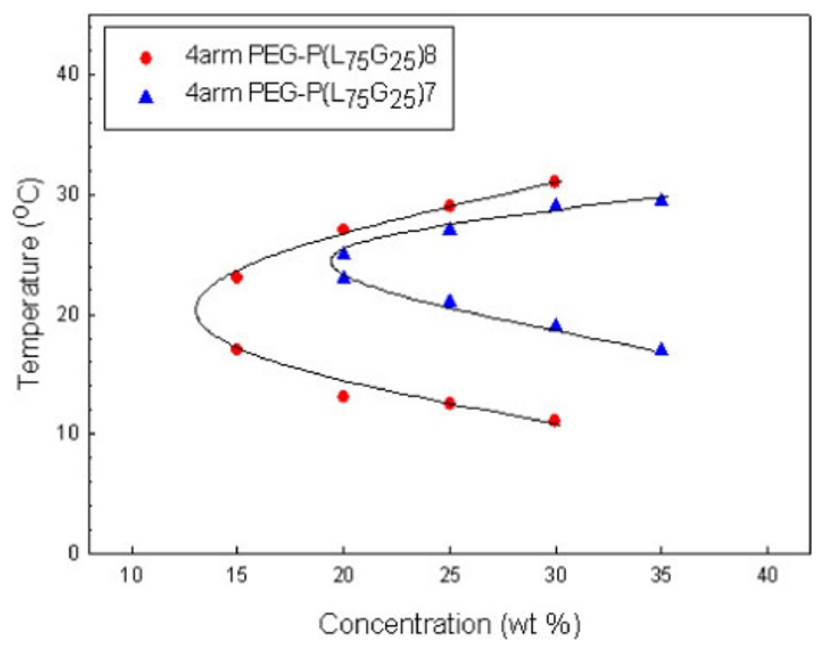

Figure 3. Effect of the molecular weight of PLGA block on the sol-gel transition of 4arm PEG-PLGAs in aqueous solutions.

$M_{\mathrm{n}, \mathrm{th}}$. However, $M_{\mathrm{n}, \mathrm{GPC}}$ was overestimated because of the use of polystyrene standard.

\section{Sol-Gel Transition}

The sol-gel transition behavior of 4arm PEG-PLGA in water was investigated with temperature change by using the tube tilting method. Figure 3 shows the sol-gel transition diagrams of 4arm PEG-PLGAs in aqueous solutions with different molecular weight of hydrophobic PLGA block. As the average degree of polymerization (DP) of PLGA block was increased from 7 to 8, the CGC moved from 19 to $13 \mathrm{wt} \%$. That is, as the molecular weight of hydrophobic PLGA block was increased, the enhanced hydrophobic interaction made 4arm PEG-PLGA form gels at lower concentration. This tendency is in accord with observation for PEG-PLGA-PEG, ${ }^{5}$ PLGA-PEG-PLGA, ${ }^{14}$ and 4arm PLGA-PEG ${ }^{17}$ in aqueous solutions.

The sol-gel transition accompanies a large change in viscosity. An abrupt increase in viscosity means sol-to-gel transition, while an abrupt decrease in viscosity means gel-tosol transition. Figure 4 shows the change in viscosity of $4 \mathrm{arm}$ PEG-P $\left(\mathrm{L}_{75} \mathrm{G}_{25}\right) 8$ aqueous solutions as a function of temperature at $15 \mathrm{wt} \%$ and $30 \mathrm{wt} \%$. At 15 and $30 \mathrm{wt} \%$, the temperature at which the viscosity starts increasing was 14 and $8{ }^{\circ} \mathrm{C}$, respectively, and the temperature at which the viscosity decreases abruptly was 25 and $32^{\circ} \mathrm{C}$, respectively. These temperatures were close to the results by the tube tilting method. The temperatures at which polymer solutions re- 


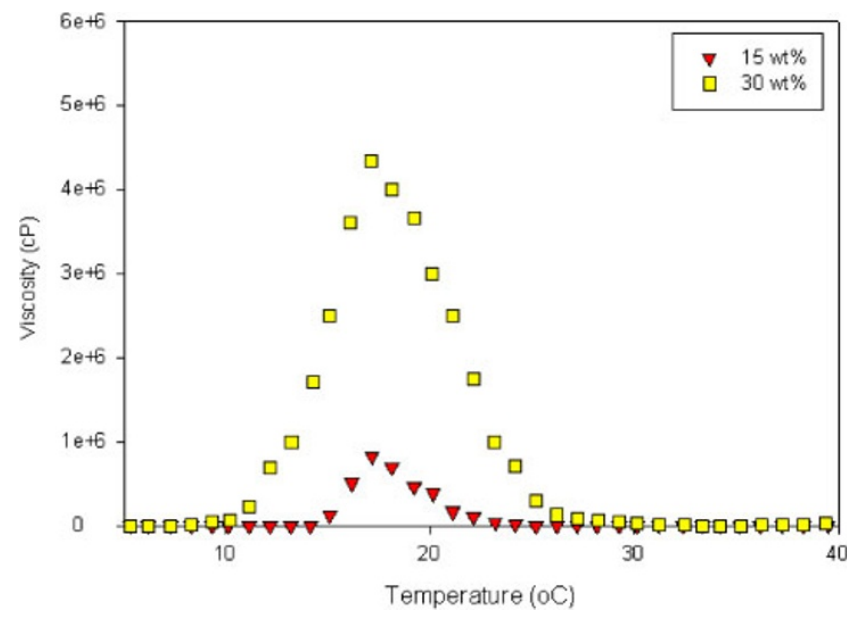

Figure 4. Viscosity change of 4arm PEG-P $\left(\mathrm{L}_{75} \mathrm{G}_{25}\right) 8$ aqueous solutions $(15 \mathrm{wt} \%, 30 \mathrm{wt} \%)$ as a function of temperature.

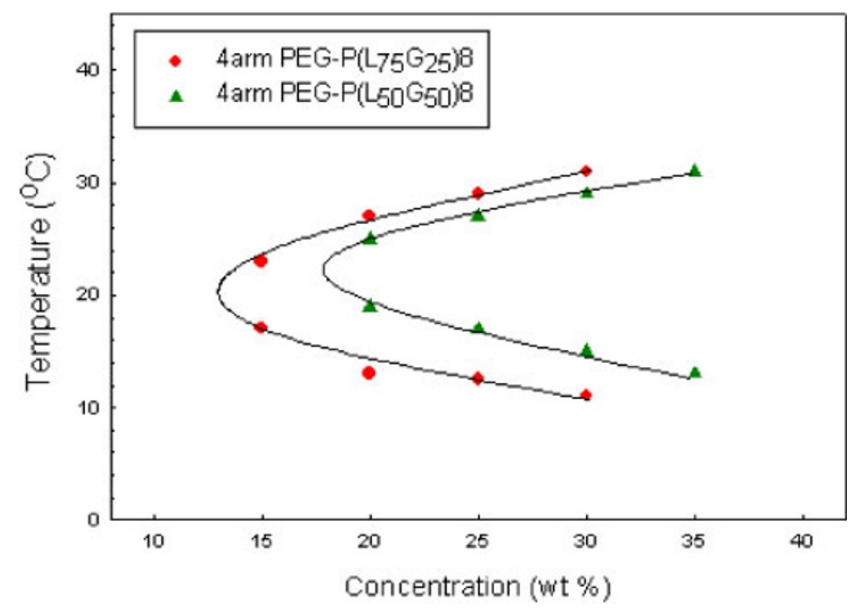

Figure 5. Effect of the relative hydrophobicity of PLGA block on the sol-gel transition of 4arm PEG-PLGAs in aqueous solutions.

mained gel state by the tube tilting method were $17-23^{\circ} \mathrm{C}$ and $11-31{ }^{\circ} \mathrm{C}$ for 15 and $30 \mathrm{wt} \%$ aqueous solutions, respectively. At each concentration, the transition temperatures measured by the viscosity changes are in good agreement with the transition temperature measured by the tube tilting method. With increasing the concentration from 15 to $30 \mathrm{wt} \%$, the maximum viscosity was increased from $8.3 \times 10^{5}$ to $4.3 \times 10^{6}$ cP. The maximum viscosity of 4arm PEG-P $\left(\mathrm{L}_{75} \mathrm{G}_{25}\right) 8(4.3 \times$ $\left.10^{6} \mathrm{cP}\right)$ was larger than that of $4 \operatorname{arm} \mathrm{P}\left(\mathrm{L}_{75} \mathrm{G}_{25}\right) 11$-PEG $(2.4 \times$ $10^{6} \mathrm{cP}$ ) at $30 \mathrm{wt} \%$ (not shown).

Figure 5 shows the effect of the relative hydrophobicity of PLGA block on the sol-gel transition behavior of 4arm PEGPLGA block copolymers in aqueous solutions. The average DP of PLGA block was fixed at 8, but [LA]:[GA] ratio was varied from $50: 50$ to $75: 25$. As the mole ratio of lactide to glycolide was increased, the CGC decreased from 18 to $13 \mathrm{wt} \%$.

We also found that the CGC of 4arm PEG-PLGA type block copolymer was lower than that of 4arm PLGA-PEG type (above $24 \mathrm{wt} \%^{17}$ ) with similar PEG content as shown in Figure 6.

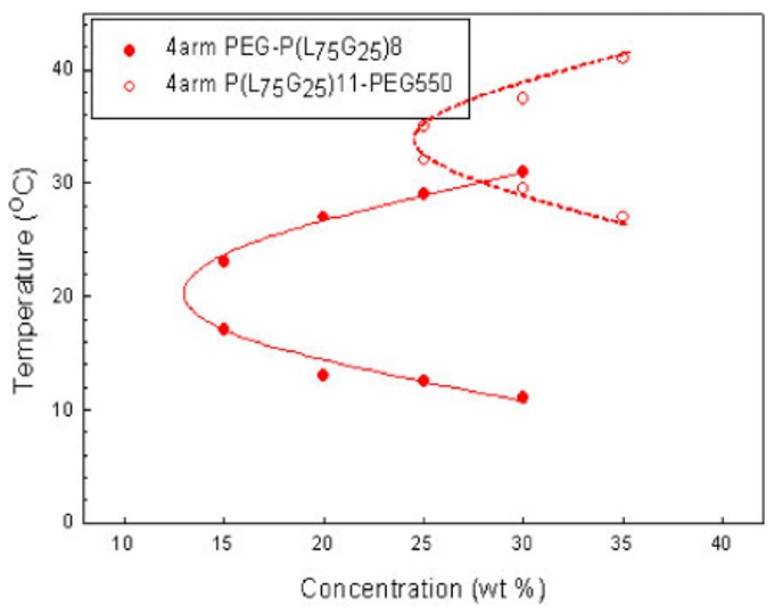

Figure 6. Effect of topology on the sol-gel transition of 4arm PEG-PLGAs in aqueous solutions. Phase diagrams of 4 arm $P\left(L_{75} G_{25}\right)$ 11-PEG550 and 4arm PEG-P $\left(L_{75} G_{25}\right) 8$ were compared.

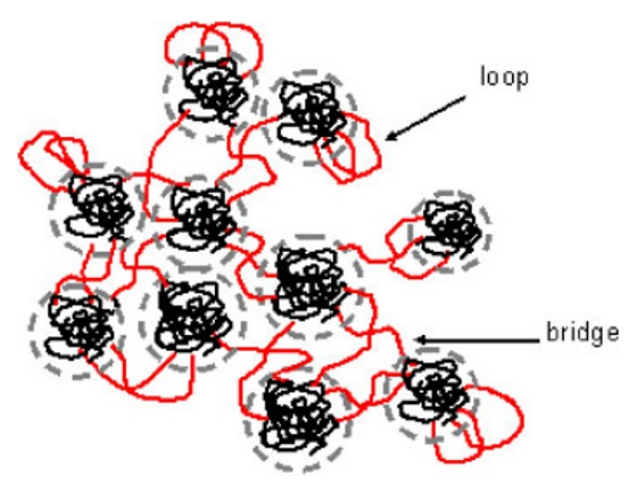

Scheme 2. The continuous networks of 4 arm PEG-PLGA

Such a low CGC can be explained in Scheme 2. 4arm PEG as a hydrophilic part is located in the center of the star polymer in 4arm PEG-PLGA system, while hydrophobic PLGA block is located in the center of the star polymer in 4arm PLGA-PEG system. So, in the latter case, micelles with the hydrophobic PLGA core (black line) and the hydrophilic dangling free PEG ends (red lines) are formed and these micelles (grey dotted line) aggregate like lipid-layer structure without connections between micelles as we suggested in the previous paper. ${ }^{17}$ However, in the former case, PLGA blocks at the end of each star polymer can be easily located in the center of different micelles having four arm PEG acting as bridges connecting each micelle. These bridges make 4arm PEGPLGA in an aqueous solution form continuous networks and have a lower CGC than 4arm PLGA-PEG. In the phase diagrams of these copolymers, it was noted that the gel regions were located in low temperature to be used as an injectable drug delivery carrier. However, the vertical shift of phase diagram can be controlled by adding some additives or increasing the PEG molecular weight. It is known that adding a small amount of NaSCN or increasing PEG molecular wieght moves phase transition curves to higher temperature regions 
without changing CGC in PLGA-PEG-PLGA ${ }^{14}$ or PEG-PLGA$\mathrm{PEG}^{5}$ system. So, even if the phase diagrams are located in rather low temperature regions, we can modulate the gellation region. These results indicate the possibility of 4arm PEGPLGA block copolymers as an injectable drug delivery carrier.

\section{Micellization}

The micelle formation of 4arm PEG-PLGA block copolymer was evidenced by the dye solubilization method and dynamic light scattering. In a hydrophobic environment, the hydrophobic dye, DPH shows higher absorbance intensity at $340-370 \mathrm{~nm}$ as a characteristic triplet peak. With the formation of micelles, it was solubilized into the hydrophobic core of micelles, resulting in the increase in the absorbance of the dye. The absorbance at $378 \mathrm{~nm}$ relative to that at $400 \mathrm{~nm}$ was plotted against polymer concentration and CMC was defined as the crossing point of the two extrapolated straight lines.

Figure 7(a) shows the UV-vis spectra of DPH as a function of polymer concentration in water. The CMC of 4arm PEGPLGA was determined as a crossing point of two straight lines as shown in Figure 7(b). CMCs of 4arm PEG-P $\left(\mathrm{L}_{75} \mathrm{G}_{25}\right) 7$, 4arm PEG-P $\left(\mathrm{L}_{75} \mathrm{G}_{25}\right) 8$, and 4arm PEG-P $\left(\mathrm{L}_{50} \mathrm{G}_{50}\right) 8$ were $0.0016,0.0014$, and $0.0024 \mathrm{wt} \%$, respectively. This CMC results indicate that 4 arm PEG-PLGA with larger molecular weight or stronger relative hydrophobicity in PLGA block forms micelles easily at lower concentration.

The free energies of micellization of 4arm PEG-PLGAs are also shown in Table II. The standard free energy change for the transfer of $1 \mathrm{~mol}$ of amphiphilic block copolymer from the solution to the micellar phase can be calculated from the following equation: ${ }^{19}$

$$
\Delta G_{\text {micelle }}^{0}=R T \ln \left(\mathrm{X}_{\mathrm{CMC}}\right)
$$

where $R$ is the gas constant, $\mathrm{T}$ is the absolute temperature, and $\mathrm{X}_{\mathrm{CMC}}$ is the critical micelle concentration in mole fraction. The negative values in standard free energies of 4arm PEG-PLGA block copolymers imply that the micellization of these star block copolymers in water is spontaneous. The more negative free energy of micellization of the 4arm PEG-P( $\left(\mathrm{L}_{75} \mathrm{G}_{25}\right) 8$ compared to those of 4arm PEG-P $\left(\mathrm{L}_{75} \mathrm{G}_{25}\right) 7$ and 4arm PEG$\mathrm{P}\left(\mathrm{L}_{50} \mathrm{G}_{50}\right) 8$ indicates that the longer PLGA block and the stronger relative hydrophobicity in PLGA block is preferable in forming the micelles.

The effective diameter of the micelle was analyzed by DLS. The size of the micelle was measured from the Stokes-Einstein relationship:

$$
\mathrm{D}=\frac{k_{B} T}{3 \pi \eta_{0} d}
$$

where $d$ is the diffusion constant, $k_{\mathrm{B}}$ is the Boltzmann's constant, $T$ is the absolute temperature, $\eta_{0}$ is the solvent viscosity, and $\mathrm{D}$ is the effective diameter of the particle.

Figure 8 shows the effective diameter of the micelles of 4arm PEG-P $\left(\mathrm{L}_{75} \mathrm{G}_{25}\right) 7$ in water $(0.5 \mathrm{wt} \%)$ with increasing (a)

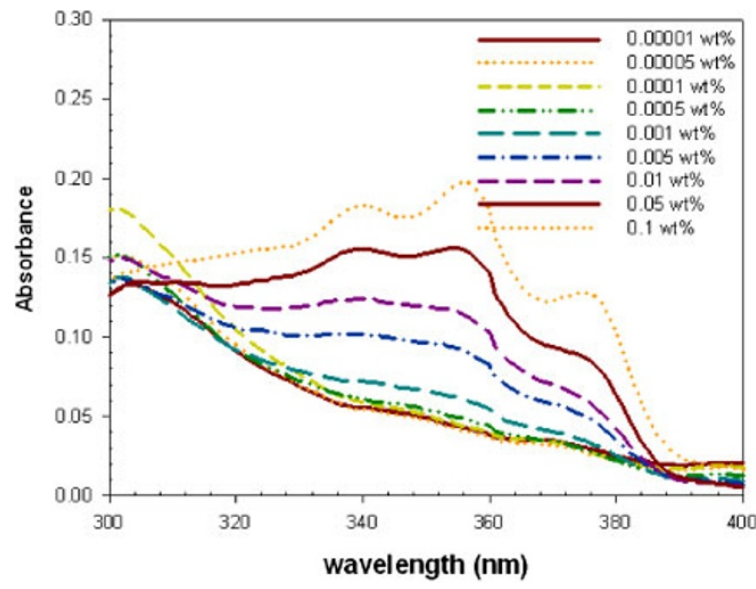

(b)

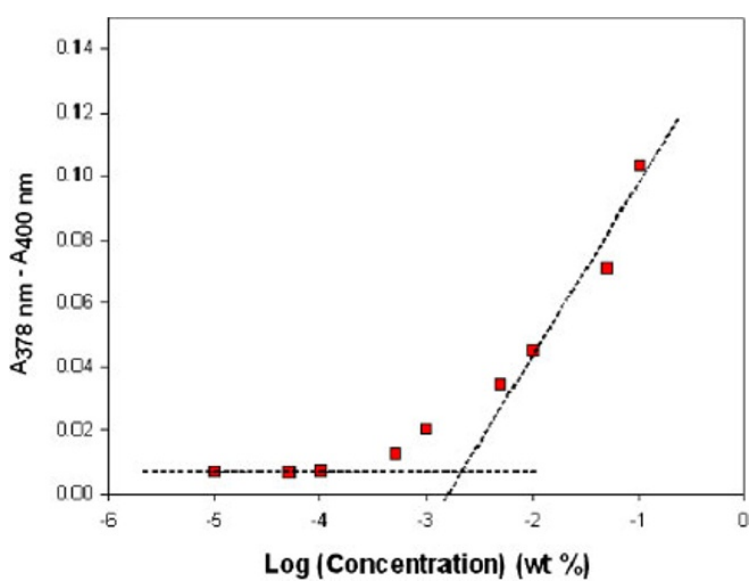

Figure 7. (a) UV-vis spectra of DPH as a function of polymer (4arm PEG$\left.P\left(L_{75} G_{25}\right) 8\right)$ concentration in water (b) Determination of critical micelle concentration of block copolymer aqueous solution at $20^{\circ} \mathrm{C}$.

Table II. CMCs and standard free energies of micellization of 4arm PEGPLGA block copolymer aqueous solutions at $20^{\circ} \mathrm{C}$

\begin{tabular}{cccc}
\hline & $\begin{array}{c}\text { CMC } \\
(\text { wt \% })\end{array}$ & $\begin{array}{c}\text { CMC } \\
(\mathrm{mol} \mathrm{fr})\end{array}$ & $\begin{array}{c}\Delta G_{\text {micelle }}^{0} \\
(\mathrm{~kJ} / \mathrm{mol})\end{array}$ \\
\hline 4arm PEG-P $\left(\mathrm{L}_{75} \mathrm{G}_{25}\right) 7$ & 0.0016 & $5.0 \times 10^{-8}$ & -40.9 \\
4arm PEG-P $\left(\mathrm{L}_{75} \mathrm{G}_{25}\right) 8$ & 0.0014 & $4.1 \times 10^{-8}$ & -41.4 \\
4arm PEG-P $\left(\mathrm{L}_{50} \mathrm{G}_{50}\right) 8$ & 0.0024 & $7.1 \times 10^{-8}$ & -40.1 \\
\hline
\end{tabular}

temperature. At $10^{\circ} \mathrm{C}$, its micelle size was about $17 \mathrm{~nm}$, which is similar to the value of $4 \operatorname{arm} \mathrm{P}\left(\mathrm{L}_{75} \mathrm{G}_{25}\right)$ 9-PEG550 with similar PEG content as reported previously. ${ }^{17}$ But, the micelle size of the 4arm PEG-P $\left(\mathrm{L}_{75} \mathrm{G}_{25}\right) 7$ with the reverse molecularstructure increased significantly as the temperature was increased. At $40^{\circ} \mathrm{C}$, the micelles were aggregated to $350 \mathrm{~nm}$ in radius. This abrupt increase in micelle size is also originated from the micelle-aggregation property with PEG bridges or loops formed from the reverse-structure of 4arm PEG-PLGA as explained in the sol-gel phase diagram. 


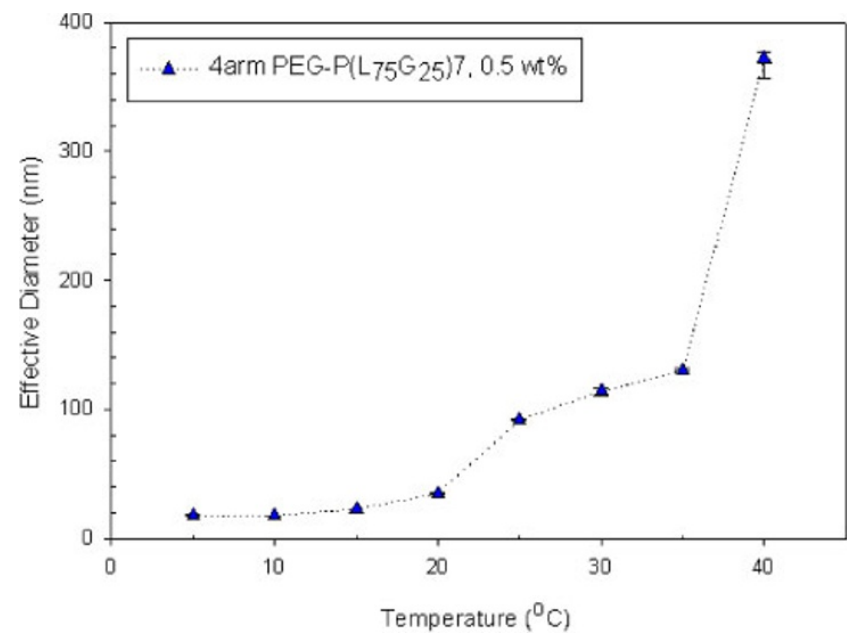

Figure 8. Micelle size of 4 arm $\mathrm{PEG}-\mathrm{P}\left(\mathrm{L}_{75} \mathrm{G}_{25}\right) 7$ in water $(0.5 \mathrm{wt} \%)$.

\section{CONCLUSIONS}

Star-shaped 4arm PEG-PLGA block copolymers with different molecular weight of PLGA block and different mole ratio of DL-lactide to glycolide were successfully synthesized by the ring-opening polymerization of DL-lactide and glycolide using 4arm PEG as an initiator and $\mathrm{Sn}(\mathrm{oct})_{2}$ as a catalyst. The $4 \mathrm{arm}$ PEG-PLGA showed temperature-sensitive sol-gel-sol transition behavior with increasing temperature. As the molecular weight and the relative hydrophobicity of hydrophobic PLGA block was increased, the CGC decreased. It seemed that the enhanced hydrophobic interaction of 4arm PEG-PLGA facilitated the formation of gels even at low concentration. We also found that 4arm PEG-PLGA had a much lower CGC than 4arm PLGA-PEG due to the difference between their molecular structures. This is due to the formation of the PEG bridges connecting the neighboring micelles and forms continuous network.
Received: July 18, 2008

Accepted: February 2, 2009

Published: March 25, 2009

\section{REFERENCES}

1. M. Malsmsten and B. Lindman, Macromolecules, 25, 5446 (1992).

2. W. Mingvanish, S. M. Mai, F. Heatley, and C. J. Booth, J. Phys. Chem. B, 103, 11269 (1999).

3. B. Jeong, M. R. Kibbey, J. C. Birnbaum, Y. Y. Won, and A. Gutowska, Macromolecules, 33, 8317 (2000).

4. B. Jeong, Y. H. Bae, and S. W. Kim, J. Controlled Release, 63, 155 (2000).

5. B. Jeong, Y. H. Bae, and S. W. Kim, Macromolecules, 32, 7064 (1999).

6. M. J. Song, D. S. Lee, J. H. Ahn, D. J. Kim, and S. C. Kim, J. Polym. Sci., Part A: Polym. Chem., 42, 772 (2004).

7. B. Jeong and A. Gutowska, Trends Biotechnol., 20, 305 (2002).

8. H. Suh, B. Jeong, R. Rathi, and S. W. Kim, J. Biomed. Mater. Res., 42, 331 (1998).

9. B. Jeong, Y. H. Bae, D. S. Lee, and S. W. Kim, Nature, 388, 860 (1997).

10. B. Jeong, D. S. Lee, J. I. Shon, Y. H. Bae, and S. W. Kim, J. Polym. Sci., Part A: Polym. Chem., 37, 751 (1999).

11. S. W. Choi, S. Y. Choi, B. Jeong, S. W. Kim, and D. S. Lee, J. Polym. Sci., Part A: Polym. Chem., 37, 2207 (1999).

12. Y. K. Sung and S. W. Kim, Kor. Polym. J., 8, 199 (2000).

13. M. S. Shim, H. T. Lee, W. S. Shim, I. Park, H. Lee, T. Chang, S. W. Kim, and D. S. Lee, J. Biomed. Mater. Res., 61, 188 (2001).

14. D. S. Lee, M. S. Shim, S. W. Kim, H. Lee, I. Park, and T. Chang, Macromol. Rapid Commun., 22, 587 (2001).

15. S. Y. Park, D. K. Han, and S. C. Kim, Macromolecules, 34, 8821 (2001).

16. S. Y. Park, B. R. Han, K. M. Na, D. K. Han, and S. C. Kim, Macromolecules, 36, 4115 (2003).

17. S. J. Lee, B. R. Han, S. Y. Park, D. K. Han, and S. C. Kim, J. Polym. Sci., Part A: Polym. Chem., 44, 888 (2006).

18. H. Li, G. E. Yu, C. Price, C. Booth, E. Hecht, and H. Hoffmann, Macromolecules, 30, 1347 (1997).

19. P. Alexandridis, J. F. Holzwarth, and T. A. Hatton, Macromolecules, 27, 2414 (1994). 